\title{
Global estimates of plasmaspheric losses during moderate disturbance intervals
}

\author{
M. Spasojevic ${ }^{1, *}$ and B. R. Sandel ${ }^{2}$ \\ ${ }^{1}$ Very Low Frequency Group, Stanford University, Stanford, CA, USA \\ ${ }^{2}$ Lunar and Planetary Laboratory, University of Arizona, Tucson, AZ, USA \\ *also at: Lockheed Martin Advanced Technology Center, Palo Alto, CA, USA
}

Received: 8 September 2009 - Revised: 12 November 2009 - Accepted: 16 December 2009 - Published: 13 January 2010

\begin{abstract}
For a set of five moderate disturbance events, we calculate the total number of $\mathrm{He}^{+}$ions removed the plasmasphere using calibrated global EUV images. In each of the events, between $\sim 0.6$ and $2.2 \times 10^{30} \mathrm{He}^{+}$ions are removed from a region of the inner magnetosphere from $L=1.5$ to 5.5. This loss constitutes between $20 \%$ and $42 \%$ of the initial $\mathrm{He}^{+}$distribution. The lost percentage is correlated with the number of hours of strongly positive solar wind electric field $\left(E_{y}>2.5 \mathrm{mV} / \mathrm{m}\right)$. Also, the total amount of material removed from the plasmasphere is estimated by using several values of the $\mathrm{He}^{+}$to $\mathrm{H}^{+}$number density ratio. The total mass lost is found to be in the range of 20 to 80 metric tons although for each individual case the estimate can vary by over $50 \%$ depending on assumed density ratio. We also attempt to distinguish between losses to the ionosphere and losses to the dayside boundary layers by estimating losses interior and exterior to the newly formed plasmapause boundary. For the events studied, losses inside the new plasmapause constitute between $24 \%$ to $54 \%$ of the total number of $\mathrm{He}^{+}$ions lost.
\end{abstract}

Keywords. Magnetospheric physics (Electric fields; Plasma convection; Plasmasphere)

\section{Introduction}

The plasma that populates the Earth's vast magnetospheric cavity originates from two sources, the ionosphere and the solar wind. Within the inner magnetosphere, the plasmasphere acts as a massive intermediate reservoir of ionospheric plasma. On a diurnal cycle, solar illumination on the dayside of the Earth results in an up-flow of ionospheric material that fills plasmaspheric flux tubes (e.g., Park, 1970, 1974a; Chappell et al., 1971; Galvan et al., 2008). On the nightside of

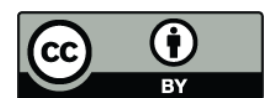

Correspondence to: $\mathrm{M}$. Spasojevic (mariaspasojevic@stanford.edu) the Earth, the ionosphere rapidly recombines, and a downward flow from the plasmasphere acts to partially maintain the nocturnal ionosphere (Park, 1970; Zhang et al., 1999; Galvan et al., 2008).

During geomagnetic storms, a more dramatic redistribution of plasmaspheric plasma occurs. Enhanced magnetospheric convection strips away the outer layers of the plasmasphere, and the combined action of convection and corotation leads to the formation of a plasmaspheric drainage plume in the afternoon local time sector (e.g., Grebowsky, 1970; Spasojevic et al., 2003). Solar wind-driven convection may be aided by internal coupling processes that produce fast but latitudinally narrow westward flow channels in the dusk sector (e.g., Anderson et al., 2001; Foster and Vo, 2002). These fast flows may significantly increase the rate of plasma transport from the duskside plasmasphere to the dayside magnetosphere during geomagnetic disturbances (Goldstein et al., 2003a). Using whistler data during a geomagnetic storm, Park (1970) estimated that $\sim 3 \times 10^{31}$ electrons and ions were removed from the plasmasphere, more than half the plasma stored in the quiet time plasmasphere, based on removal of essentially all plasma in a belt extending globally from $L=3.5$ to 5 .

In addition, significant plasma depletions occur interior to the new plasmapause boundary (Park and Carpenter, 1970; Park, 1973; Carpenter et al., 1993; Chi et al., 2000) Flux tubes inside the shrinking plasmapause remain on closed drift paths and thus losses are likely not due to convection. In order to explain the plasmaspheric density reductions as well as nighttime enhancements in the mid-latitude ionosphere, Park (1971) first proposed a draining of the flux tubes along the magnetic field lines and consequent dumping of plasma into the ionosphere. Enhanced convection during storms moves nightside plasmaspheric plasma from higher to lower L-shells with smaller volumes, thus increasing the plasma pressure in the magnetic flux tube and downward plasma fluxes. This draining from the plasmasphere

Published by Copernicus Publications on behalf of the European Geosciences Union. 
may contribute significantly to the positive enhancements observed in the nightside mid-latitude ionosphere (Park, 1974b; Jakowski et al., 1990; Szuszczewicz et al., 1998). However, other studies have provided different thoughts to the interpretation. Clilverd et al. (2000) questioned if the downward flux could suffice or sustain long enough to explain the observed plasmaspheric depletion. Studies by Chi et al. (2000) and Kawano et al. (2006) have conjectured that the internal depletion of the plasmasphere could be due to the reduced level of ionospheric outflow during concurrent negative ionospheric storms.

The large scale redistribution of cold plasma during storm intervals has wide ranging implications for a variety of other magnetospheric and ionospheric processes. Storm-time plasmaspheric structures have been found to be strongly associated with ionospheric density features, and specifically plasmaspheric plumes have been linked to the ionospheric storm enhanced density (SED) feature as well as polar cap patches (Su et al., 2000; Foster et al., 2002, 2004). Within the inner magnetosphere, the distribution of cold plasma directly affects resonant wave-particle interactions and thus profoundly influences energetic particle distributions (e.g., Horne et al., 2005; Spasojevic et al., 2005). Eroded plasmaspheric material is transported sunward and is regularly observed near the dayside magnetopause boundary (Freeman, 1969; Carpenter et al., 1993; Chen and Moore, 2006). Here, the enhanced dayside plasma density may limit the rate of reconnection (through a reduction in the Alfvén speed) and thus influence the global convection pattern (Hesse and Birn, 2004; Chen and Moore, 2006; Borovsky and Denton, 2006). After reaching the dayside magnetopause, plasmaspheric material can then be transported on reconnected field lines over the polar cap and down the magnetotail ( $\mathrm{Su}$ et al., 2000, $2001 \mathrm{a}, \mathrm{b})$. It is unclear what portion of the formerly plasmaspheric material is drained down the magnetotail and lost to the solar wind as opposed to entering the plasma sheet and being eventually recirculated into the inner magnetosphere (Freeman et al., 1977; Elphic et al., 1997; Borovsky et al., 1997). Plasma sheet ion density and composition measurements (e.g., Lennartsson and Shelley, 1986) suggest that although some fraction of this eroded plasmaspheric material may join the plasma sheet, the vast majority of it is likely lost to the solar wind before the field line reconnects in the distant magnetotail.

In order to further understand the potential influence of plasmaspheric material on other magnetospheric processes, it is important to quantify the amount of material removed from the inner magnetosphere during disturbance intervals. Previous attempts to quantify plasmaspheric losses during storms have relied on projections based on local measurements (Park, 1970; Elphic et al., 1997; Foster et al., 2004). Here we use data collected by the global plasmaspheric imager that operated onboard the IMAGE spacecraft (Burch, 2000) in order to make true global estimates of plasmaspheric losses. For a set of five moderate disturbance inter- vals, we calculate the global loss of plasmaspheric $\mathrm{He}^{+}$ions (the second most abundant plasmaspheric species). We relate the total loss to degree of solar wind driving, specifically, the solar wind electric field. Further, we attempt to estimate the amount of material lost inside versus outside the new plasmaspause boundary. Finally, using several estimates of the $\mathrm{He}^{+}$to $\mathrm{H}^{+}$density ratio, we calculate the total mass of material removed from the inner magnetosphere during the events.

\section{Observations}

The Extreme Ultraviolet (EUV) imager (Sandel et al., 2000) provided the first global images of the Earth's plasmasphere (e.g., Sandel et al., 2001, 2003). EUV imaged the $\mathrm{He}^{+}$distribution in the inner magnetosphere by detecting resonantly scattered 30.4-nm solar radiation. The intensity of the detected emission is directly proportional to the $\mathrm{He}^{+}$column density along the line of sight from the spacecraft (located at high altitude above the Northern Hemisphere polar cap) through the plasmasphere. The images are calibrated using the instrument response and the $30.4 \mathrm{~nm}$ solar EUV flux as measured by the SOHO CELIAS/SEM and TIMED/SEE instruments such that the color scale indicates the $\mathrm{He}^{+}$column density (ions per $\mathrm{cm}^{2}$ ). The uncertainty in the EUV sensitivity is estimated to be $\pm 25 \%$.

The EUV images are mapped to the Solar Magnetic (SM) equatorial plane using a dipole field model and the minimum$L$ technique of Roelof and Skinner (2000). The minimum- $L$ technique maps each pixel of the EUV image to the equatorial crossing of the minimum dipole $L$-shell along the line of sight. This technique is applicable since densities in the plasmasphere rapidly fall with increasing $L$-shell, and thus the innermost regions penetrated by a given line of sight contribute the most to the observed 30.4-nm intensity (Sandel et al., 2003). Nevertheless, there are contributions to the column density from higher $L$ values mapped at any given equatorial pixel. This becomes important for estimates of loss inside the new plasmapause location in Sect. 5. We also note that the mapping of images to the equatorial plane first requires that the Earth's center position be manually selected, a procedure which constitutes a small source of uncertainty in the mapping.

Since the EUV technique relies on solar illumination, the column density values in the shadow of the Earth are invalid. For the May/June 2001 period, we find that the Earth's shadow primarily affects the images (reduces the nightside intensity) out to a radial distance of about $3.5 R_{\mathrm{E}}$. Beyond that distance, the image intensity appears to be insensitive to the shadow possibly as a result of the large dipole tilt during those months. In addition, the instrument has some residual sensitivity at longer wavelengths. At low altitudes, the images are contaminated by atmospheric $\mathrm{He} 58.4-\mathrm{nm}$ and $\mathrm{O}^{+}$ 53.9-nm emissions. Therefore, for the analysis performed 


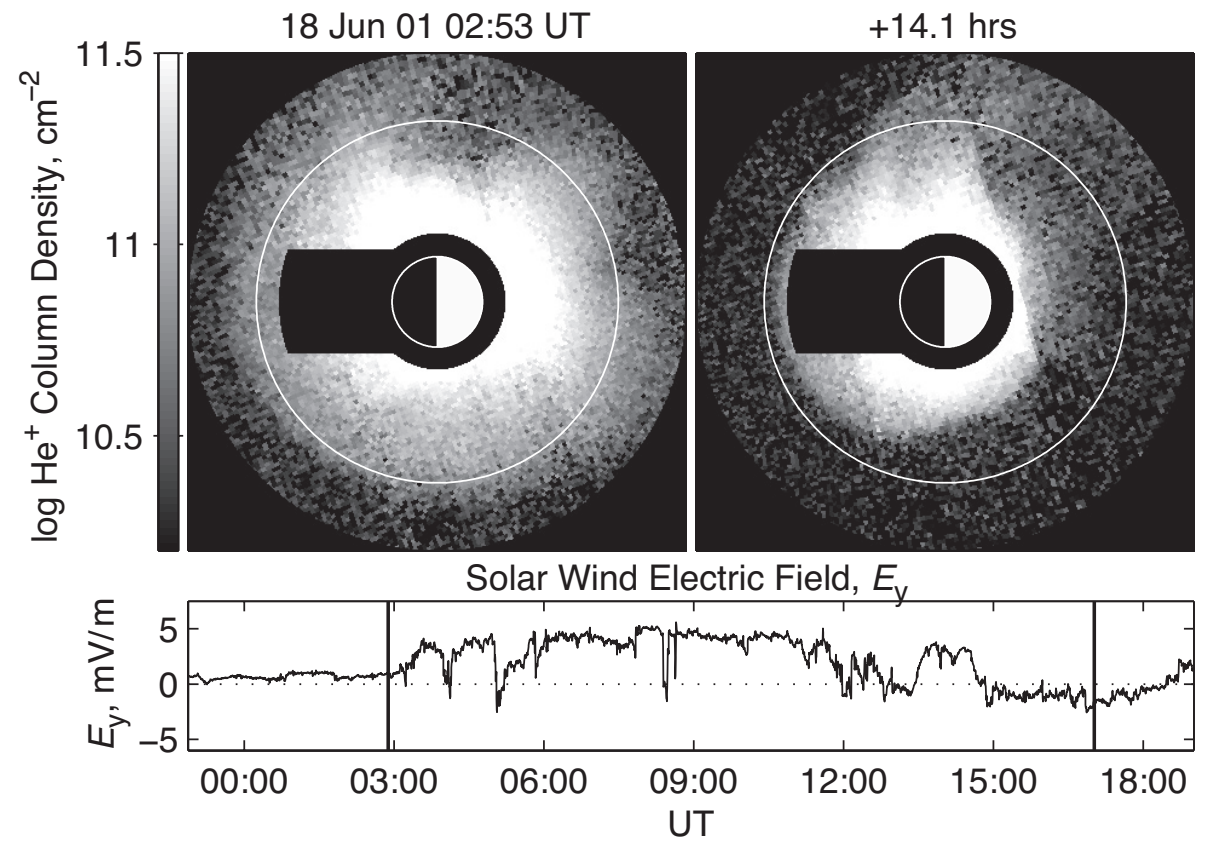

Fig. 1. Equatorially mapped EUV images of the plasmasphere before the disturbance onset (left) and at the beginning of the disturbance recovery (right) for 18 June 2001 with the sun being to the right of the images. The image has been masked out for $L<1.5, L>5.5$, and in the Earth's shadow region. The white circle indicates $L=4$. The images are calibrated and the gray scale indicates the log of the He ${ }^{+}$ column density. The bottom panel is the solar wind electric field, $E_{y}$, derived from ACE spacecraft measurements and the two vertical bars indicate the times of the two images.

here, the region inside $1.5 R_{\mathrm{E}}$ and in the shadow of the Earth extending to $3.5 R_{\mathrm{E}}$ is masked out. In addition, the images are masked outside of $5.5 R_{\mathrm{E}}$ in order to compare identical viewing areas for all events.

\section{Event analysis}

Five disturbance periods are examined in order to study the global loss of plasmaspheric material. These events were selected from a relatively active solar interval in 2001 and also at a time when the apogee of IMAGE was high in the Northern Hemisphere and thus the EUV field of view contained the majority of the plasmasphere in a near-equatorial projection for a long period of time. The event periods are 8-9 May 2001 (minimum Sym-H = -72 nT), 28 May 2001 (-48 nT), 2 June $2001(-47 n T), 18$ June $2001(-84 n T)$ and 26 June 2001 ( -33 nT). For each disturbance, two EUV images were selected, one from before or near the disturbance onset and another from near the end of the main phase or the beginning of recovery. The two images were selected one orbit apart with the requirement that at all magnetic local times, $L \leq 5.5$ was within the field of view. The total time between the "before" and "after" images was between 12.4 and $15.5 \mathrm{~h}$ for each of the five events.

Figure 1 shows an example from 18 June 2001. The EUV image at 02:53 UT (left panel) captured the $\mathrm{He}^{+}$distribu- tion in the plasmasphere before the disturbance onset. The plasmasphere is expanded with the plasmapause located beyond $4 R_{\mathrm{E}}$ (white circle) at most local times. The image from $\sim 14.1 \mathrm{~h}$ later (right) captured the beginning of the recovery phase. The plasmapause has been eroded to low $L$ and the remnant of a plasmaspheric plume (e.g., Spasojevic et al., 2003; Goldstein and Sandel, 2005) can be seen at dusk. Qualitatively, a comparison of the two EUV images shows that a large volume of plasma has been removed especially from the outer plasmasphere. Of particular interest is that in the noon sector, plasma has been eroded down to $L \simeq 2$. The lower panel of Fig. 1 shows the solar driving during the intervening time between the images. Plotted is the solar wind electric field, $E_{y}$ that is the solar wind velocity GSM X-component, $v_{\mathrm{x}}$, times the GSM z-component of the IMF. These data were obtained from the ACE MAG (Smith et al., 1998) and SWEPAM (McComas et al., 1998) instrument and time shifted to the magnetopause. The solar wind electric field is a proxy indicator for the strength of magnetospheric convection (e.g., Shepherd, 2007). During the intervening time between the two images, the IMF $B_{z}$ had been strongly southward for many hours, corresponding to a positive value of $E_{y}$. A plasmaspheric plume had formed in the afternoon sector and after the northward IMF turning at $\sim 15: 00 \mathrm{UT}$, began to rotate across dusk. 
(a) 08 May 01 18:24UT
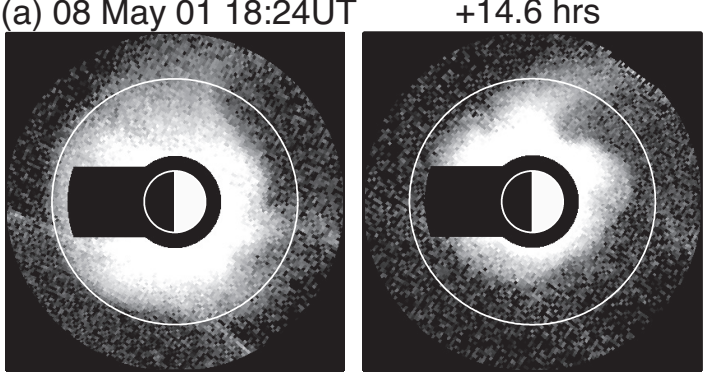

L) $\begin{array}{r}5 \\ 0 \\ -5\end{array}$

$\begin{array}{lllll}15: 00 & 19: 00 & 23: 00 & 03: 00 & 07: 00\end{array}$

(b) 28 May 01 09:00UT
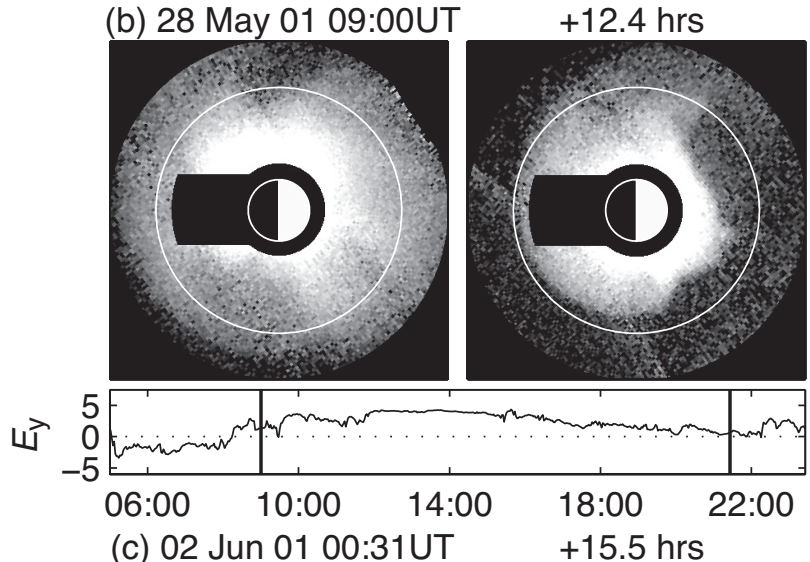

(c) 02 Jun 01 00:31UT
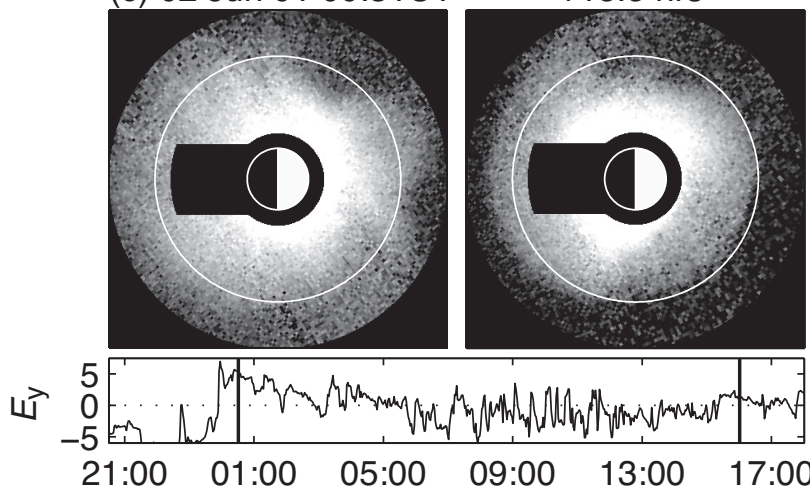

(d) 26 Jun 01 09:58UT
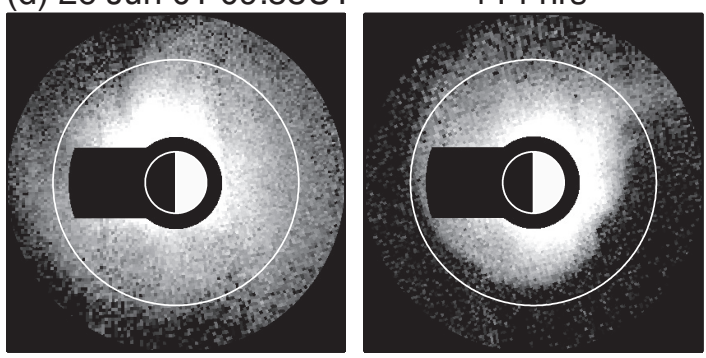

L4 $\begin{aligned} & 5 \\ & 0 \\ & -5\end{aligned}$

Fig. 2. Same as Fig. 1 for the other 4 study intervals.

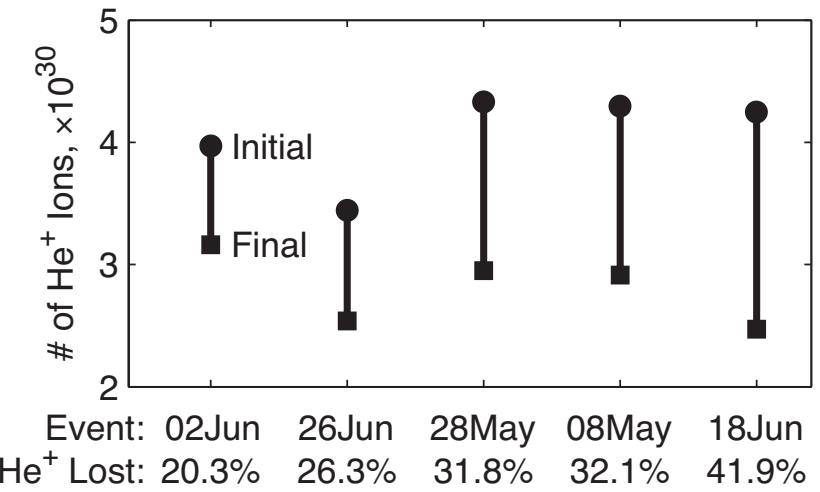

Fig. 3. The initial and final $\mathrm{He}^{+}$abundance as well as the loss percentage for each of the five events.

The other four events are displayed in Fig. 2. As can be seen, both the initial and final distribution of $\mathrm{He}^{+}$ions in the plasmasphere is highly variable from event to event, both in terms of the radial extent of the plasmapause as well as the density of plasma interior to the boundary.

\subsection{Calculation of $\mathrm{He}^{+}$losses}

For each of the five disturbance periods, the total number of $\mathrm{He}^{+}$ions in the plasmasphere before and after the disturbance was calculated. This was done by integrating the $\mathrm{He}^{+}$ column density over the entire equatorial plane (excluding the masked out regions). Figure 3 shows the initial and final number of $\mathrm{He}^{+}$ions in the inner magnetosphere for each event. The events are ordered by the $\mathrm{He}^{+}$loss percentage, that is the fraction of the initial distribution of $\mathrm{He}^{+}$that was removed during the event interval. The initial amount of $\mathrm{He}^{+}$ in the inner magnetosphere for these events was on the order of $\sim 3.4-4.3 \times 10^{30}$ ions and $\sim 20-40 \%$ of the initial distribution was removed within a period of $12.4-15.5 \mathrm{~h}$. Table 1 also lists the percentage of $\mathrm{He}^{+}$ions lost and the total number of $\mathrm{He}^{+}$ions lost for each event. The number of ions lost also includes an estimate of the error associated with the measurement based on the uncertainty in the EUV sensitivity. The total number of $\mathrm{He}^{+}$ions lost is in range of $\sim 0.6-2.2 \times 10^{30}$ for the five events studied. In this analysis, we have made no attempt to account for the expected dayside refilling nor nightside depletion of plasmaspheric material. Our calculations simply represent the total change in the $\mathrm{He}^{+}$content between the two images. We also note that there may be contributions to the column density along the line of sight from IMAGE that are outside the plasmasphere. However, these contributions are expected to be small, i.e., significantly less than the uncertainty in the EUV sensitivity. 


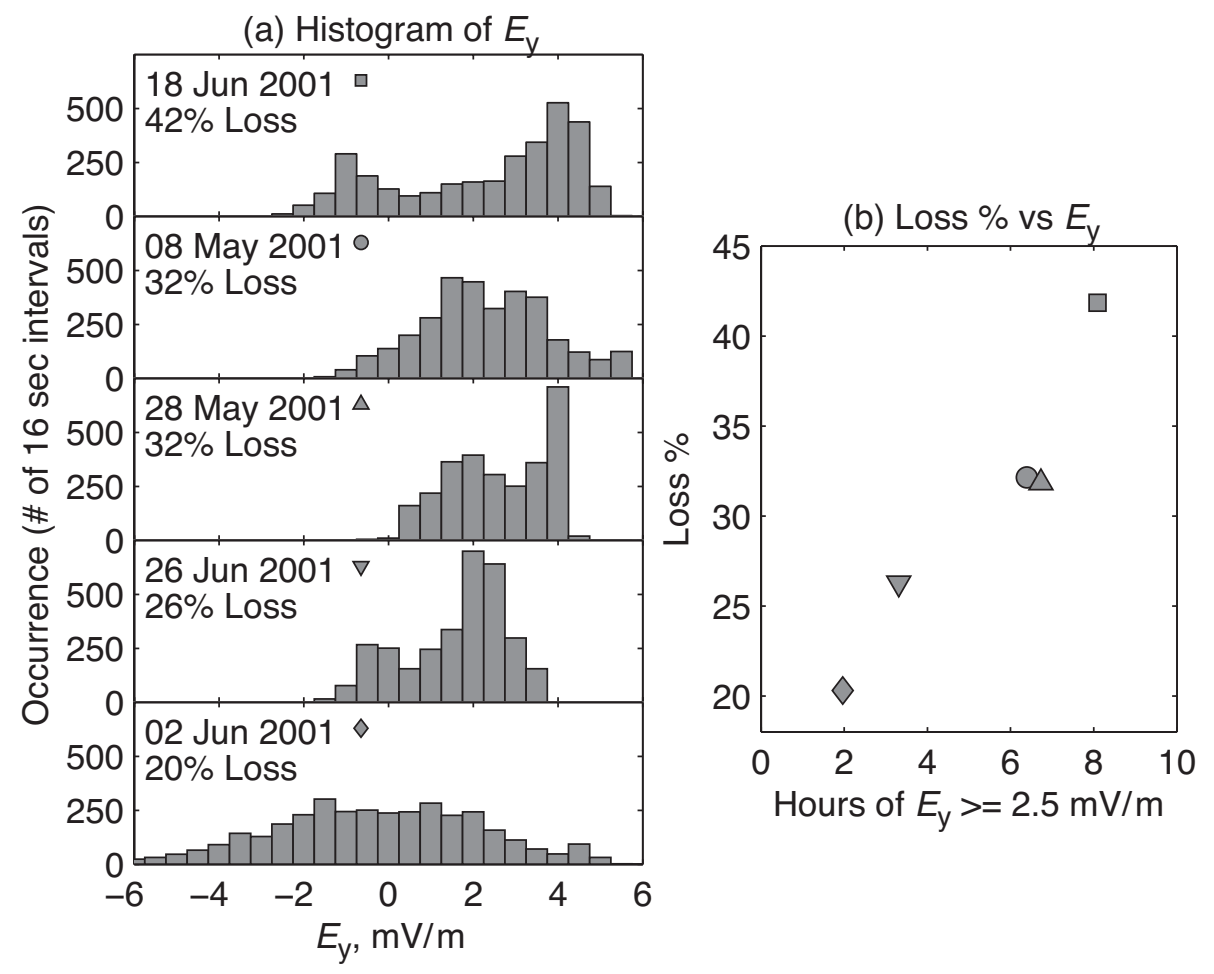

Fig. 4. (a) A histogram of the solar wind $E_{y}$ during each of the disturbance intervals. (b) The relationship between the percentage of He ${ }^{+}$ lost during the event and the number of hours of $E_{y} \geq 2.5$.

Table 1. Summary of the loss calculations for the five disturbance periods. ${ }^{\text {a }}$ The total ions lost calculation uses the $\alpha$ ratio from (Craven et al., 1997).

\begin{tabular}{ccccc}
\hline Event & $\% \mathrm{He}^{+}$Lost & $\mathrm{He}^{+}$Ions Lost & Total Ions Lost & $E_{y} \geq 2.5 \mathrm{mV} / \mathrm{m}$ \\
\hline 2 Jun 2001 & $20.3 \%$ & $0.8 \pm 0.2 \times 10^{30}$ & $1.9 \pm 0.5 \times 10^{31}$ & $2.0 \mathrm{~h}$ \\
26 Jun 2001 & $26.3 \%$ & $0.9 \pm 0.2 \times 10^{30}$ & $1.9 \pm 0.5 \times 10^{31}$ & $3.3 \mathrm{~h}$ \\
28 May 2001 & $31.8 \%$ & $1.4 \pm 0.3 \times 10^{30}$ & $2.9 \pm 0.7 \times 10^{31}$ & $6.7 \mathrm{~h}$ \\
8 May 2001 & $32.1 \%$ & $1.4 \pm 0.3 \times 10^{30}$ & $2.2 \pm 0.5 \times 10^{31}$ & $6.4 \mathrm{~h}$ \\
18 Jun 2001 & $41.9 \%$ & $1.8 \pm 0.4 \times 10^{30}$ & $2.3 \pm 0.6 \times 10^{31}$ & $8.1 \mathrm{~h}$ \\
\hline
\end{tabular}

\section{Correlation of the loss with $E_{y}$}

An attempt was made to correlate the percentage of $\mathrm{He}^{+}$lost to various geophysical parameters such as the magnetic indices $\mathrm{Kp}$ and Dst as well as solar wind parameters number density, velocity, and IMF. The best correlation was found with the strength and direction of the IMF $B_{z}$ component and similarly the derived quantity solar wind $E_{y}$. This result is perhaps not surprising given that global magnetospheric convection is driven by magnetic field line reconnection between oppositely directed solar wind and terrestrial magnetic fields.

Figure 4 a shows a histogram of the value of $E_{y}$ during the disturbance interval (time between the solid vertical lines in Figs. 1 and 2). Occurrence is defined as the number of $16 \mathrm{~s}$ samples in each range of $E_{y}$ values. The events have been ordered from top to bottom by decreasing total percentage loss. For the event with the lowest percentage loss, 2 June 2001, the values of $E_{y}$ are distributed among positive and negative values, with a low occurrence of strongly positive values. As the loss percentage increases so does the occurrence of positive $E_{y}$, and the event with highest loss percentage has a peak in the histogram for $E_{y}=4 \mathrm{mV} / \mathrm{m}$. Figure $4 \mathrm{~b}$ shows a linear relationship between the total number of hours of $E_{y} \geq 2.5 \mathrm{mV} / \mathrm{m}$ and the loss percentage. A $2.5 \mathrm{mV} / \mathrm{m}$ solar wind electric field is equivalent to a solar wind velocity $v_{\mathrm{x}}=-500 \mathrm{~km} / \mathrm{s}$ and an IMF $B_{z}=-5 \mathrm{nT}$. The total number of hours of $E_{y}>0$ did not correlate with loss percentage as well since the 3 middle events (28 May 2001; 8 May 2001; and 26 

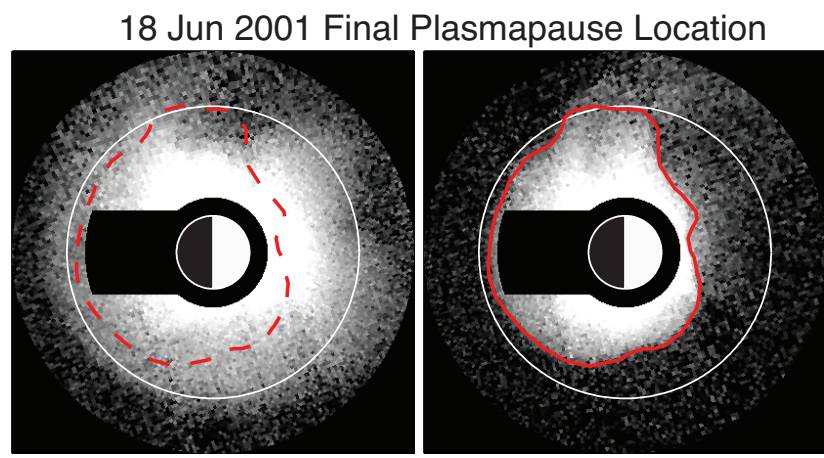

Fig. 5. The EUV images for 18 Jun 2001 with the final plasmapause location selected in the right image (red line) and overlaid on the initial plasmasphere image on the left (dashed red line).

June 2001) all had more total hours of $E_{y}>0$ than the largest loss event (18 June 2001). Nevertheless, the many hours of strongly positive $E_{y}$ appear to be important in contributing to the large loss percentage on 18 June 2001.

\section{Estimation of the partitioning of losses}

Next, we make a first order estimate the amount of $\mathrm{He}^{+}$ lost inside versus outside the new plasmapause boundary. In the second of the two images for each case, a plasmapause boundary is manually selected using the technique of Goldstein et al. (2003b) with the exception that the plasmapause must be single valued at a given local time. The selected plasmapause location for 18 June 2001 event is shown in the right panel of Fig. 5, and the final plasmapause location is overlaid on the initial image in the left panel. As can be seen, the restriction of the single valued plasmapause causes the plasmaspheric plume, located near 18 MLT, to be somewhat artificially cut off. In order to select the single valued plasmapause near the plume region, we follow the western edge of the plume until it begins to curve to earlier local times and then draw the boundary across the plume to its eastern edge. Once the boundary is selected, the losses are calculated on either side of the final plasmapause location. Figure 6 shows the total number of $\mathrm{He}^{+}$ions that were lost inside versus outside of the newly established plasmapause boundary. For example, for the 18 June 2001 event, $76 \%$ of the loss is estimated to have occurred outside the boundary while the remaining $24 \%$ of the loss occurred inside. For all except the 2 June 2001 event, a greater percent of the total loss occurred outside the new plasmapause.

The calculation of the partitioning of the losses inside versus outside of the plasmapause is considered a first order estimate for several reasons. First of all, losses within the shadow region are not accounted for. For each event, the shadow region is almost entirely contained within the new plasmapause and comprises $\sim 8-14 \%$ of the area inside that

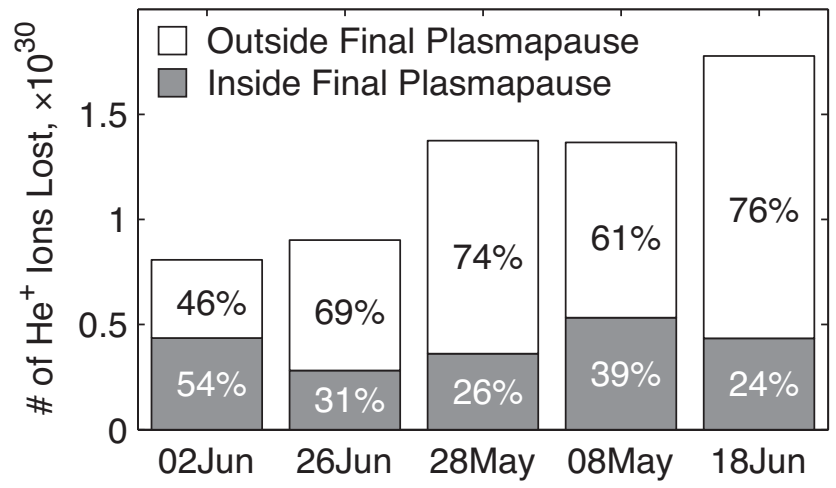

Fig. 6. The total number of $\mathrm{He}^{+}$ions removed from the plasmasphere is broken down by the estimated amount lost inside versus outside the new plasmapause boundary. For example on 18 June $2001,76 \%$ of the plasma loss occurred outside the new plasmapause boundary.

boundary. Thus, we expect that as a result of a lack of measurements in the shadow region, the percentage of the loss occurring within the plasmapause is under-estimated using the current technique. On the other hand, the minimum$L$ technique used in mapping the images to the equatorial plane includes in every pixel contributions from field lines at higher $L$. This will then result in an over-estimate of the losses inside the new boundary. The effect of the image mapping could be partially overcome through image inversion, which would produce a three-dimensional density distribution. However, this procedure also has uncertainty, since the inversion inherently depends on the assumed field aligned distribution. Even after the inversion, densities in the shadow region would be unknown. In the end, we believe that our first order estimate of the loss partitioning is a reasonable one based the competing uncertainties in the calculation.

\section{Estimation of the total mass of material lost}

Next, we estimate the total number of ions as well as the mass of material lost from the plasmasphere for each of the disturbed periods. For this calculation, an assumption needs to be made as to the relative concentration of $\mathrm{He}^{+}$to the other ion species, primarily $\mathrm{H}^{+}$and $\mathrm{O}^{+}$. One simple approach is to use a constant density ratio between species throughout the entire plasmasphere. However, a more accurate estimate can be made by using an empirical relationship derived from a statistical study of data from the retarding ion mass spectrometer (RIMS) on the Dynamics Explorer spacecraft (Craven et al., 1997).

Using DE-1/RIMS data over a 3.25 year period covering both high and low solar activity, Craven et al. (1997) examined the $\mathrm{He}^{+}$to $\mathrm{H}^{+}$number density ratio defined as 


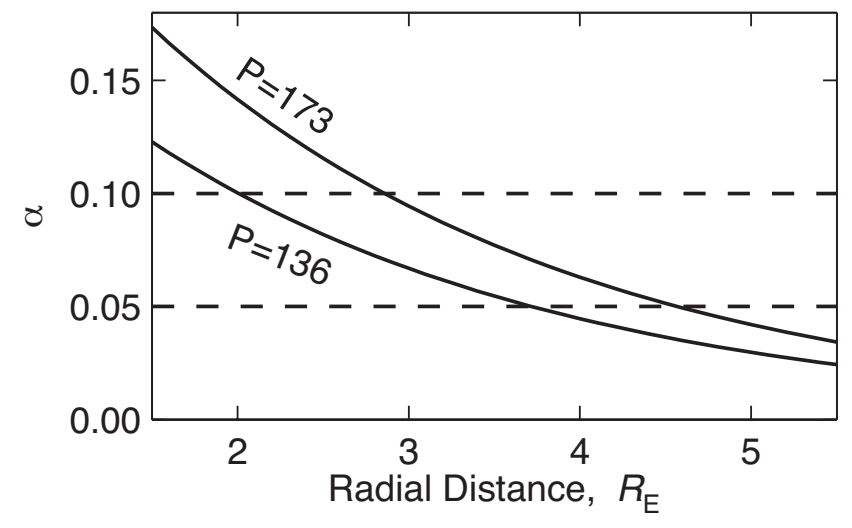

Fig. 7. The $\mathrm{He}^{+}$to $\mathrm{H}^{+}$density ratio from the Craven et al. (1997) formula as a function of radial distance for the minimum $(P=135)$ and maximum $(P=172)$ solar activity of the five study intervals.

$\alpha \equiv \frac{n_{\mathrm{He}^{+}}}{n_{\mathrm{H}^{+}}}$

and found that $\alpha$ is primarily a function of geocentric distance and the solar EUV input. The ratio appeared to have no dependence on geomagnetic activity, and a weak dependence on local time, season, latitude and $L$ value. The authors empirically derived the follow expression for the ratio:

$$
\begin{array}{r}
\log _{10} \alpha=-1.541-0.176 r+8.557 \times 10^{-3} P \\
-1.458 \times 10^{-5} P^{2}
\end{array}
$$

where $r$ is geocentric radial distance in $R_{\mathrm{E}}$ and $P$ is a proxy measure of solar activity defined by

$P=\frac{F_{10.7}+F_{10.7 \mathrm{~A}}}{2}$

where $F_{10.7 \mathrm{~A}}$ is the 81 -day average of the daily $10.7-\mathrm{cm}$ solar flux $\left(F_{10.7}\right)$.

Figure 7 shows the density ratio computed using Eq. (1) for the minimum $(P=135)$ and maximum $(P=172)$ solar activity of the five study intervals. Based on this dependence of $\alpha$ on $R_{\mathrm{E}}$ and since EUV measures only the $\mathrm{He}^{+}$content, using a constant density ratio will tend to overestimate the total number density at small radial distances and underestimate the total number density at larger radial distances.

For each of the five study intervals, the total mass of plasma removed from the plasmasphere was estimated 3 different ways: 1) using Eq. (1) 2) using a constant ratio $\alpha=0.10,3$ ) using $\alpha=0.05$. Unfortunately, a large statistical evaluation of the $\mathrm{O}^{+}$concentration is not currently available. Thus, we use a constant $\mathrm{H}^{+}$to $\mathrm{O}^{+}$density ratio of 0.01 for all three estimates consistent with case studies by Horwitz et al. (1990). The total mass was calculated as the sum of the total masses of $\mathrm{H}^{+}, \mathrm{He}^{+}, \mathrm{O}^{+}$ions with an equal number of

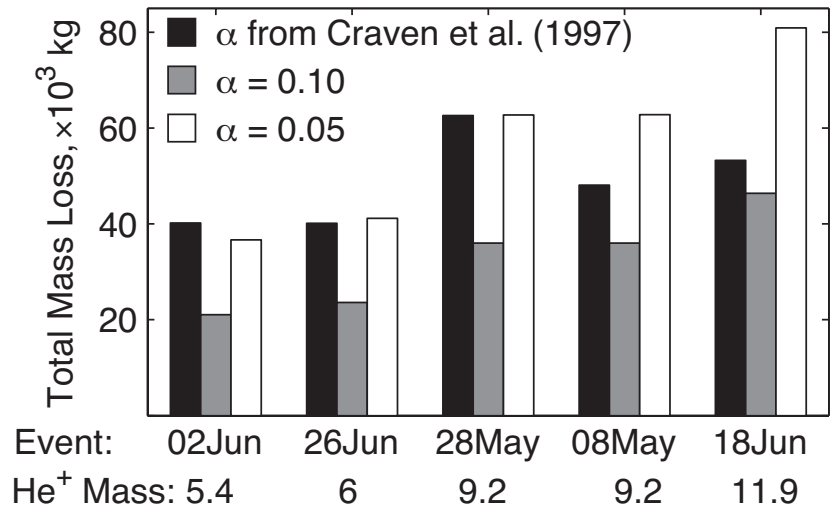

Fig. 8. The total mass of plasma in metric tons removed from the inner magnetosphere for each of the disturbance intervals calculated using two constant density ratios, $\alpha=0.10$, and $\alpha=0.05$ and by allowing the ratio to vary as a function of radial distance and solar EUV input.

electrons. As can be seen in Fig. 8, the total mass removed from the plasmasphere for the moderate disturbance events is rather large, on the order of several tens of metric tons. It is important to note that the choice of $\alpha$ can cause the total estimated mass to vary significantly. When using a constant ratio, the total mass loss scales linearly with $\mathrm{He}^{+}$mass lost (show below the event date). However, the initial plasma distribution as well as the $\mathrm{He}^{+}$mass lost contributes to the total mass lost when using Eq. (1). For example, on both the 28 May 2001 and 8 May 2001 events, about 9.2 metric tons of $\mathrm{He}^{+}$was lost, and thus when using the constant ratio, the total mass lost is similar between the two events. However, when estimating the total mass lost using Eq. (1), the 28 May 2001 loss estimate is $\sim 15$ tons higher than 8 May 2001. This result is due to the fact that the initial plasma distribution on 28 May 2001 (Fig. 2) extends to higher radial distances where the $\mathrm{He}^{+}$distribution underestimates the total distribution according to Craven et al. (1997). Table 1 lists the total number of ions removed from the plasmasphere, using the Craven et al. (1997) formula and along with an estimate of the associated error in the measurement based on the EUV sensitivity. For the events examined here, the total number of ions lost is in the range of $\sim 1.4-2.9 \times 10^{31}$.

\section{Summary}

For a set of moderate disturbance periods (none with Sym$\mathrm{H}<-100 \mathrm{nT}$ ), we calculate the total amount of $\mathrm{He}^{+}$removed from the plasmasphere using calibrated global EUV images. In each of the events, between $\sim 0.6$ and $2.2 \times 10^{30} \mathrm{He}^{+}$ions are removed from a region of the inner magnetosphere from $L=1.5$ to 5.5. This loss constitutes between $20 \%$ and $42 \%$ of the initial $\mathrm{He}^{+}$distribution. The lost percentage is correlated with the number of hours of strongly positive solar 
wind electric field $\left(E_{y}>2.5 \mathrm{mV} / \mathrm{m}\right)$. From these calculations, the total amount of material removed from the plasmasphere is estimated by using several values of the $\mathrm{He}^{+}$to $\mathrm{H}^{+}$number density ratio. The total mass lost is found to be in the range of 20 to 80 metric tons although for each individual case the estimate can vary by over $50 \%$ depending on assumed density ratio.

Plasma removed from the plasmasphere during disturbance periods is either transported to the dayside boundary layers or lost to the ionosphere. Although in the current analysis we cannot distinguish between these two mechanisms, we did attempt to estimate the loss inside versus outside the new plasmapause boundary. For the events studied, losses inside the new plasmapause constitute between 24 and 54\% of the total number of $\mathrm{He}^{+}$ions lost confirming past local reports of significant internal plasmasphere depletion during storms (Park and Carpenter, 1970; Park, 1973; Carpenter et al., 1993; Chi et al., 2000)

The calculations presented here were based on global plasmaspheric data, and our results are consistent with previous projections of plasmaspheric losses based on local measurements. Park (1970) estimated plasmaspheric losses during a storm to be $\sim 3 \times 10^{31}$ electrons based whistler data indicating the removal of plasma in a belt extending from $L=3.5$ to 5. Similarly in our study, we estimate that the total number of ions lost from the plasmasphere varied from $\sim 1.4$ to $2.9 \times 10^{31}$ using the $\mathrm{He}^{+}$to $\mathrm{H}^{+}$density ratio formulated by Craven et al. (1997) although we note that our estimate includes the range of $L=1.5$ to 5.5. Several studies have estimated the rate at which plasma within the plasmaspheric plume is transport sunward during disturbance intervals. Elphic et al. (1997) used geosynchronous measurements of ion density and an estimated convection speed to project that ions could be transported out of the inner magnetosphere at a rate of $0.37 \times 10^{27}$ ions/s. Similarly, Foster et al. (2004) used ground-based radar measurements and an EUV measurement of column densities in the plume during a large storm event to estimate a loss rate of $1.5 \times 10^{27} \mathrm{ions} / \mathrm{s}$. To compare to the current study, we can calculate the average loss rate by dividing the total number of ions lost by the number of hours of $E_{y}>2.5 \mathrm{mV} / \mathrm{m}$ (see Table 1) and further assuming that on average $65 \%$ of the ions lost are transported toward the dayside boundary layers (mean value of our estimated losses outside the new plasmapause, see Fig. 6). Thus, we estimate a average loss rate of $\sim 0.38-2.1 \times 10^{27} \mathrm{ions} / \mathrm{s}$ consistent with the Elphic et al. (1997) and Foster et al. (2004) studies.

In conclusion, solar-wind driven magnetospheric convection results in a massive redistribution of cold plasma in the magnetosphere with several tens of metric tons of material being removed from the plasmasphere even for relatively modest storm intervals. The quantification of loss performed here is an important step in understanding the implications of this mass redistribution on other magnetospheric and ionospheric processes including wave-particle interactions, dayside reconnection, and magnetosphere-ionosphere coupling.
Acknowledgements. The work at Stanford University was support by NASA grant NNX08AF31G. The work at Lockheed Martin was supported by NASA grant NNX07AG52G. The work at University of Arizona was support by NASA grant NNX07AG46G.

Topical Editor R. Nakamura thanks D. Galvan and another anonymous referee for their help in evaluating this paper.

\section{References}

Anderson, P. C., Carpenter, D. L., Tsuruda, K., Mukai, T., and Rich, F. J.: Multisatellite observations of rapid subauroral ion drifts (SAID), J. Geophys. Res., 106, 29585-29600, doi:10.1029/ 2001JA000128, 2001.

Borovsky, J. E. and Denton, M. H.: Effect of plasmaspheric drainage plumes on solar-wind/magnetosphere coupling, Geophys. Res. Lett., 33, 20101, doi:10.1029/2006GL026519, 2006.

Borovsky, J. E., Thomsen, M. F., and McComas, D. J.: The superdense plasma sheet: Plasmaspheric origin, solar wind origin, or ionospheric origin?, J. Geophys. Res., 102, 22089-22106, doi: 10.1029/97JA02469, 1997.

Burch, J. L.: IMAGE mission overview, Space Sci. Rev., 91, 1-14, 2000.

Carpenter, D. L., Giles, B. L., Chappell, C. R., Décréau, P. M. E., Anderson, R. R., Persoon, A. M., Smith, A. J., Corcuff, Y., and Canu, P.: Plasmasphere dynamics in the duskside bulge region: A new look at old topic, J. Geophys. Res., 98, 19243, doi:10. 1029/93JA00922, 1993.

Chappell, C. R., Harris, K. K., and Sharp, G. W.: The dayside of the plasmasphere., J. Geophys. Res., 76, 7632-7647, doi:10.1029/ JA076i031p07632, 1971.

Chen, S.-H. and Moore, T. E.: Magnetospheric convection and thermal ions in the dayside outer magnetosphere, J. Geophys. Res. (Space Physics), 111, 3215, doi:10.1029/2005JA011084, 2006.

Chi, P. J., Russell, C. T., Musman, S., Peterson, W. K., Le, G., Angelopoulos, V., Reeves, G. D., Moldwin, M. B., and Chun, F. K.: Plasmaspheric depletion and refilling associated with the September 25, 1998 magnetic storm observed by ground magnetometers at $\mathrm{L}=2$, Geophys. Res. Lett., 27, 633, doi:10.1029/ 1999GL010722, 2000.

Clilverd, M. A., Jenkins, B., and Thomson, N. R.: Plasmaspheric storm time erosion, J. Geophys. Res., J. Geophys. Res., 105, 12997-13008, 2000.

Craven, P. D., Gallagher, D. L., and Comfort, R. H.: Relative concentration of $\mathrm{He}+$ in the inner magnetosphere as observed by the DE 1 retarding ion mass spectrometer, J. Geophys. Res., 102, 2279-2290, doi:10.1029/96JA02176, 1997.

Elphic, R. C., Thomsen, M. F., and Borovsky, J. E.: The fate of the outer plasmasphere, Geophys. Res. Lett., 24, 365-368, doi: 10.1029/97GL00141, 1997.

Foster, J. C. and Vo, H. B.: Average characteristics and activity dependence of the subauroral polarization stream, J. Geophys. Res., 107, 1475, doi:10.1029/2002JA009409, 2002.

Foster, J. C., Erickson, P. J., Coster, A. J., Goldstein, J., and Rich, F. J.: Ionospheric signatures of plasmaspheric tails, Geophys Res. Lett., 29, 130 000-1, doi:10.1029/2002GL015067, 2002.

Foster, J. C., Coster, A. J., Erickson, P. J., Rich, F. J., and Sandel, B. R.: Stormtime observations of the flux of plasmaspheric ions to the dayside cusp/magnetopause, Geophys. Res. Lett., 31, 8809, doi:10.1029/2004GL020082, 2004. 
Freeman, J. W., Hills, H. K., Hill, T. W., Reiff, P. H., and Hardy, D. A.: Heavy ion circulation in the earth's magnetosphere, Geophys. Res. Lett., 4, 195-197, doi:10.1029/GL004i005p00195, 1977.

Freeman Jr., J. W.: Magnetospheric wind., Science, 163, 10611062, doi:10.1126/science.163.3871.1061, 1969.

Galvan, D. A., Moldwin, M. B., and Sandel, B. R.: Diurnal variation in plasmaspheric He+ inferred from extreme ultraviolet images, J. Geophys. Res., 113, 9216, doi:10.1029/2007JA013013, 2008.

Goldstein, J. and Sandel, B. R.: The Global Pattern of Evolution of Plasmaspheric Drainage Plumes, Washington D.C. American Geophysical Union Geophysical Monograph Series, 159, 1, 2005.

Goldstein, J., Spasojević, M., Reiff, P. H., Sandel, B. R., Forrester, W. T., Gallagher, D. L., and Reinisch, B. W.: Identifying the plasmapause in IMAGE EUV data using IMAGE RPI in situ steep density gradients, J. Geophys. Res., 108(A4), 1147, doi: 10.1029/2002JA009475, 2003a.

Goldstein, J., Spiro, R. W., Sandel, B. R., Wolf, R. A., Su, S.-Y., and Reiff, P. H.: Overshielding event of 28-29 July 2000, Geophys. Res. Lett., 30(8), 1421, doi:10.1029/2002GL016644, 2003b.

Grebowsky, J. M.: Thermal Plasma Near the Plasmapause, NASA Special Publication, 251, 63, 1970.

Hesse, M. and Birn, J.: On the cessation of magnetic reconnection, Ann. Geophys., 22, 603-612, 2004, http://www.ann-geophys.net/22/603/2004/.

Horne, R. B., Thorne, R. M., Shprits, Y. Y., Meredith, N. P., Glauert, S. A., Smith, A. J., Kanekal, S. G., Baker, D. N., Engebretson, M. J., Posch, J. L., Spasojevic, M., Inan, U. S., Pickett, J. S., and Décréau, P. M. E.: Wave acceleration of electrons in the Van Allen radiation belts, Nature, 437, 227-230, doi: 10.1038/nature03939, 2005.

Horwitz, J. L., Comfort, R. H., Richards, P. G., Chandler, M. O., Chappell, C. R., Anderson, P., Hanson, W. B., and Brace, L. H.: Plasmasphere-ionosphere coupling. II - Ion composition measurements at plasmaspheric and ionospheric altitudes and comparison with modeling results, J. Geophys. Res., 95, 7949-7959, doi:10.1029/JA095iA06p07949, 1990.

Jakowski, N., Putz, E., and Spalla, P.: Ionospheric storm characteristics deduced from satellite radio beacon observations at three European stations, Ann. Geophys., 8, 343-351, 1990.

Kawano, H., Chi, P. J., Kumamoto, A., and Morioka, A.: In situ observation at $L=2.3-5$ by the Akebono satellite of the plasmaspheric depletion during the September 1998 magnetic storm, J. Geophys. Res., 111, 4204, doi:10.1029/2005JA011134, 2006.

Lennartsson, W. and Shelley, E. G.: Survey of 0.1- to $16-\mathrm{keV} / \mathrm{e}$ plasma sheet ion composition, J. Geophys. Res., 91, 3061-3076, doi:10.1029/JA091iA03p03061, 1986.

McComas, D. J., Bame, S. J., Barker, P., Feldman, W. C., Phillips, J. L., Riley, P., and Griffee, J. W.: Solar Wind Electron Proton Alpha Monitor (SWEPAM) for the Advanced Composition Explorer, Space Sci. Rev., 86, 563-612, doi:10.1023/A: 1005040232597, 1998.

Park, C. G.: Whistler Observations of the Interchange of Ionization between the Ionosphere and the Protonosphere, J. Geophys. Res., 75, 4249-4260, doi:10.1029/JA075i022p04249, 1970.

Park, C. G.: Westward electric fields as the cause of nighttime enhancements in electron concentrations in midlatitude $\mathrm{F}$ region., $\mathrm{J}$.
Geophys. Res., 76, 4560-4568, doi:10.1029/JA076i019p04560, 1971.

Park, C. G.: Whistler Observations of the Depletion of the Plasmasphere during a Magnetospheric Substorm, J. Geophys. Res., 78, 672-683, doi:10.1029/JA078i004p00672, 1973.

Park, C. G.: Some Features of Plasma Distribution in the Plasmasphere Deduced From Antarctic Whistlers, J. Geophys. Res., 79, 169-173, doi:10.1029/JA079i001p00169, 1974a.

Park, C. G.: A morphological study of substorm-associated disturbances in the ionosphere., J. Geophys. Res., 79, 2821-2827, doi: 10.1029/JA079i019p02821, 1974b.

Park, C. G. and Carpenter, D. L.: Whistler evidence of large-scale electron-density irregularities in the plasmasphere., J. Geophys. Res., 75, 3825-3836, doi:10.1029/JA075i019p03825, 1970.

Roelof, E. C. and Skinner, A. J.: Extraction of ion distributions from magnetospheric ENA and EUV images, Space Sci. Rev., 91, 437-459, 2000.

Sandel, B. R., Broadfoot, A. L., Curtis, C. C., King, R. A., Stone, T. C., Hill, R. H., Chen, J., Siegmund, O. H. W., Raffanti, R., Allred, D. D., Turley, R. S., and Gallagher, D. L.: The Extreme Ultraviolet Imager Investigation for the IMAGE Mission, Space Sci. Rev., 91, 197-242, 2000.

Sandel, B. R., King, R. A., Forrester, W. T., Gallagher, D. L., Broadfoot, A. L., and Curtis, C. C.: Initial results from the IMAGE extreme ultraviolet imager, Geophys. Res. Lett., 28, 1439-1442, doi:10.1029/2001GL012885, 2001.

Sandel, B. R., Goldstein, J., Gallagher, D. L., and Spasojevic, M.: Extreme Ultraviolet Imager Observations of the Structure and Dynamics of the Plasmasphere, Space Sci. Rev., 109, 25-46, doi: 10.1023/B:SPAC.0000007511.47727.5b, 2003.

Shepherd, S. G.: Polar cap potential saturation: Observations, theory, and modeling, J. Atmos. Solar-Terr. Phys., 69, 234-248, doi: 10.1016/j.jastp.2006.07.022, 2007.

Smith, C. W., L’Heureux, J., Ness, N. F., Acuña, M. H., Burlaga, L. F., and Scheifele, J.: The ACE Magnetic Fields Experiment, Space Sci. Rev., 86, 613-632, doi:10.1023/A:1005092216668, 1998.

Spasojevic, M., Goldstein, J., Carpenter, D. L., Inan, U. S., Sandel, B. R., Moldwin, M. B., and Reinisch, B. W.: Global response of the plasmasphere to a geomagnetic disturbance, J. Geophys. Res. (Space Physics), 108, 1340, doi:10.1029/2003JA009987, 2003.

Spasojevic, M., Thomsen, M. F., Chi, P. J., and Sandel, B. R.: Afternoon Subauroral Proton Precipitation Resulting from Ring Current-Plasmasphere Interaction, Washington D.C. American Geophysical Union Geophysical Monograph Series, 159, 85, 2005.

Su, Y.-J., Borovsky, J. E., Thomsen, M. F., Elphic, R. C., and McComas, D. J.: Plasmaspheric material at the reconnecting magnetopause, J. Geophys. Res., 105, 7591-7600, doi:10.1029/ 1999JA000266, 2000.

Su, Y.-J., Borovsky, J. E., Thomsen, M. F., Dubouloz, N., Chandler, M. O., Moore, T. E., and Bouhram, M.: Plasmaspheric material on high-latitude open field lines, J. Geophys. Res., 106, 60856096, doi:10.1029/2000JA003008, 2001a.

Su, Y.-J., Thomsen, M. F., Borovsky, J. E., and Foster, J. C.: A linkage between polar patches and plasmaspheric drainage plumes, Geophys. Res. Lett., 28, 111-114, doi:10.1029/2000GL012042, 2001b.

Szuszczewicz, E. P., Lester, M., Wilkinson, P., Blanchard, P., Abdu, 
M., Hanbaba, R., Igarashi, K., Pulinets, S., and Reddy, B. M.: A comparative study of global ionospheric responses to intense magnetic storm conditions, J. Geophys. Res., 103, 11665-11684, doi:10.1029/97JA01660, 1998.
Zhang, S. R., Fukao, S., and Oliver, W. L.: Data modeling and assimilation studies with the MU radar, J. Atmos. Solar-Terr. Phys., 61, 563-583, 1999. 